\title{
Magical Aspects in Chandra Shyam Dangol's Stone Sculptures
}

\section{Yam Prasad Sharma}

Assistant Professor in English, Lalit Kala Campus, Tribhuvan University

Email: yamprasadsharma@gmail.com

\section{DOI: https://doi.org/ 10.3126/irjmmc.v2i4.41553}

Received: December 7, 2021; Revised \& Accepted: December 14, 2021; Published:December 22,2021

(C) Copyright: Sharma (2021).

\section{ABSTRACT}

Chandra Shyam Dangol's stone sculptures are magical and mystical suggesting supernatural and spiritual aspects related to wisdom and enlightenment. Unusual images and symbols have been put together. On the surface level, the combination appears strange and contrary but as we go through the myths related to the artworks, we find the underlined logic and coherent composition. The recurrent icons, images and symbols are the figures of deities, lotus, mudras (gestures) and asanas (postures) of meditating characters that are combined in an unusual manner. They provide a sense of miraculous and thrilling spiritual experience. Breaking the monotony of mundane material existence, the works renew our perception. The aesthetic experience leads toward the awareness of the self and the universe and inspires for the harmonious existence of the individual in the world. Because of the mythical and spiritual contents, the sculptures appear to be mystical. The research area covers the stone sculptures of Chandra Shyam Dangol. About a dozen sculptures have been observed for the research but only four works have been interpreted in this paper. The paper attempts to trace the magical elements in his compositions and throw light on their significance. The study follows the qualitative research method to support the thesis statement since the interpretation of artworks may be multiple depending on viewers, time and place.

Keywords: Enlightenment, magical, mystical, myth, spirituality, symbol

\section{INTRODUCTION}

Chandra Shyam Dangol, one of the renowned Nepali sculptors, shares symbols, ideas, icons and iconography from traditional Nepali arts. The works represent images and characters from the myths. The images and symbols in the sculptures suggest concepts beyond the presented contents. The unusual combination of the images, figures and symbols makes the works magical (Balter, 2009). The mysticism in the works presents the spiritual values that assist the viewers to achieve harmonious existence in the world. This paper supports this statement by interpreting the artworks. Before doing this, Dangol and his works are introduced briefly. Dangol was born and grew up inKhokana, Lalitpur, a traditional Newar town full of woodcarvings, stone sculptures, Newar architecture (Dixit, 2011). The artist learned basic skills of stone carving in his own family when he was very young since his father himself was a traditional sculptor (Khokana Stone Carving, 2021). He sharpened his 
craftsmanship and broadened his creative visions from Fine Arts Campus and Central Department of Fine Arts, Tribhuvan University, Kathmandu, Nepal. He earned his Master in Fine Arts (Sculpture), and at present, he is a Ph.D. scholar at TU.

Dangol has been carving stones and making fine sculptures for more than three decades. He has made hundreds of stone sculptures including the monumental sculpture of Manjushree, the biggest stone sculpture of Nepal (33 ft), which has been installed in Manjushree Park Chobhar (Nagarik Daily, 2018). National and international museums, art galleries, institutions and private collectors have collected his sculptures (Shrestha, 2018). He has been passing his legacy of art, techniques and visions in stone carving to the students of art at Sirjana College of Fine Arts, Tribhuvan University, Kathmandu, Nepal. Dangol also worked as a distinguished professor at Suzhou Art and Design Technology Institute, Suzhou, China. He is a member of Nepal Heritage Society, Artist's Society of Nepal Nepal and Nepal Handicrafts Federation, (Khokana Stone Carving, 2021 ). The artist has received coveted awards like 'Achievement Award -2008' by Oita Asian Sculpture Exhibition, Japan, 'National Best Enterpreniur'-2006/07 by Small Scale Cottage Industry, Government of Nepal, and Fine Arts Special Award - 2011 by Nepal Academy of Fine Arts, Kathmandu, Nepal. Dangolhas a big stone carving studio in Lalitpur where he carves images in colossal rocks assisted by 10 artisans. The sculptor himself shares his experience of creating stone sculptures:

I want to be one of the instigators to usher in a new renaissance of traditional art in Nepal. . . one needs to have been embedded in art theory and art history - to be immersed in an art world. . . I found solace and escape in the wonderful world of sculptures. Carving a figure out of a slab of stone gave me immense pleasure. I worked hard, and my work sustained me. I always wanted to work on colossal statues that stand tall and capture the imagination of the people, so I decided to take a gamble and invested all my savings on a couple of large pieces of stone. I also hired a few artisans and started overseeing their work as opposed to carving the rock myself. (qtd. in Thapa, 2016, pp.19-20).

Due to his dedication, craftsmanship and confidence, the artist has made many masterpieces of stone sculptures. The colossal size and fine form make his artworks different from other sculptures.

Magical aspects in Chandra Shyam Dangol's stone sculptures are related to the Hindu and Buddhist myths. His artworks are connected to figures and characters of the myths (Gorkhapatra Daily, 2018). His sculptures of Shivalinga are the visual and tactile expressions based on the characters like Lord Shiva and Shakti, his consort as mentioned in Shivapurana. The figures of PanchBuddhas and Bodhisattvas are related to the myths of Mahayana Buddhism. Myths provide supernatural character to the person and events. The shapes, figures, actions and narrations go beyond the realistic representation. They convey a sense of superpower and divinity which cannot be proved physically and scientifically but we perceive and feel a sense of spiritual undercurrent. Symbolically, metaphorically and analogically, the myths and artworks present a quest for invisible power and the adjustment of the self in the 
world (Langer, 1979). In the subtle sense, the creations capture the philosophical essence of our life. This research paper analyzes artworks from a mythical perspective.

\subsection{Literature Review}

Newar art and cultural landscape in Khokana influenced the young artist to initiate the creative process. Stone sculptures in the ambiance are his particular attractions. Due to his dedication and continuous work, he achieved specialization in stone carving (Sourya National Daily, 2018). Firstly, he acquired the native tradition of Nepali art following the forefathers and studying myths related to artworks. He refined the traditional techniques of stone carving and added new dimensions to his creations. The exposure of his fine sculptures to international viewers has helped to create the identity of Nepal beyond the national border. $\mathrm{He}$ has taken part in more than seventy national and international sculpture exhibitions. $\mathrm{He}$ participated in World Shanghai Expo 2010 with his $12 \mathrm{ft}$ tall Bodhisattva sculpture. His Maitreya Buddha sculpture (18 ft high) has been installed in Bara district.

Dangol'ssculpturesdepict the gods and goddesses of Hindu and Buddhist myths. The representations of DhyaniBuddhas, Bodhisattvas, Lokesvara, Manjushree, Lord Shiva, Shivalinga, goddess Laxmi, Kuber and Lord Ganesha are the recurrent characters in his compositions (Kantipur National Daily, 2018). His sculpturespresentNepal's cultural heritage in aesthetic forms. Chandra Shyam Dangol'sartworks revitalize the cultural tradition of Kathmandu valley in visual form (Tourism Mail, 2018). He is one of the sculptors who craft monumental stone sculptures in Nepal.

Dangol exploits symbols to suggest the unseen meanings of the sculptures to the audience. His symbolic expressions signify the abstract and plural ideas. The symbols in his works provide depth to the aesthetic composition. The figures suggest something beyond themselves. Lotus is a frequent symbol in his sculptures that signifies purity (Ward, 1952). His Shivalinga is the symbol of unity in Shiva and Shakti. We can understand his works through our imagination and the knowledge of myths (Paudyal, 2018). The meanings of the works remain in silence until they are interpreted. The artist tries to express the invisible aspects of reality by means of visible shapes. This research traces the symbols in his artworks and attempts to show their significances.

Dangol's sculptures suggest deeper significance. The works imply immaterial or ideal essences. They evoke the intuitions of inner life and try to convey the underlined mystery of existence in spite of the difficulty in perceiving precise significance (Gurung, 2019). The presentation hints at the silent reality. The works can be interpreted in multiple ways. There is a different reality beyond the visible physical world. The intangible reality may be glimpsed through the creative imagination and the knowledge of the myths (Bajracharya, 2018). The sculptures stand at a critical juncture and connect the visible and invisible reality through the suggestive power of the compositions. Most of the works suggest the concept of enlightenment. Human beings are attached to the mundane material world but they should attempt to achieve nirvana transcending the physical reality. This is a transformation of our consciousness.

\subsection{Research Gap}


The review of literature depicts that Chandra Shyam Dangol's stone sculptures have been studied from various perspectives but their magical features have not been explored well. This paper traces magical features in his stone sculptures and shows their significance.

\section{Research Questions}

This study answers the following research questions:

1 . Why are there unusual combinations of images and symbols in Chandra Shyam Dangol's artworks?

2 . Do they have underlined logic and significance despite the strange and contrary combination on the surface?

3 . What is the significance of his sculptures?

\section{Research Objectives}

The study has the following objectives:

-to find the magical aspects in Chandra Shyam Dangol's stone sculptures

-to interpret his sculptures and find the significance of magical aspects

\section{MATERIALS AND METHOD}

The research area of this study covers the stone sculptures of Dangol which have been studied from the perspective of myths. The paper uses qualitative research, for the artworks have been interpreted to support the thesis statement, and the interpretation of the sculptures can be multiple depending on the viewers. His sculptures are primary sources, and the books and articles on art are secondary sources of the study. Artist's studio has been visited to view the artworks. The artist and art critics have been interviewed.

\section{Myth, Magic and Art}

Dangol presents magical images and symbols in his stone sculptures taking viewers to Hindu and Buddhist mythical roots. Mythical symbols and narratives come to the individual artists from the collective memory of the community and society. The symbols in myths and artworks are the common heritage of mankind that are frequently represented in visuals. Jung (1992) argues that the collective unconscious is the reservoir of archetypal symbols and images that surface recurrently throughout history in the form of art and architecture including painting, sculpture and poetry (Rampley, 1997). Such mythical images provide shape to the experience of our forefathers. When we closely analyze archetypal symbols in sculpture, they suggest a pattern of experiences of the ancestors. According to Frye (1992), mythical symbols are the recurring images that communicate underlined significance in society. Campbell (1971) argues that archetypes are the basic images that inspire magical rituals, mythology and inner vision in the history of human culture. Artworks include archetypes that are existing in the collective unconscious. Such primordial images and symbols communicate subtle codes to the individual members of the community.

Archetypal symbols and images have existed since ancient times, and they are persistently inherited from one generation to another generation unconsciously through myths, rituals, arts and cultures. These primordial images exist in the collective memory of the community. Within cultures and myths, there lie ancestral experiences of human beings (Sharma, 2021 ). An individual in the community is unconsciously guided and shaped by the collective experiences of the past. In the community, myths connect one individual to another 
individual along with the entire group. In other words, archetypes are parts of human civilization.

The combination of images and symbols in mythical narrative appear strange and magical but they have underlined significance. They may be metaphors of abstract ideas. The interpretations of composition depict the close link with lived experience of the people. They are about the hope of happiness, fear of the unknown, protection from danger and adjustment in the context. Myths and artworks are interconnected. The magical characters and events in myths guide the community to a meaningful existence. The magical aspects in arts also have underlined significance related to spirituality and human existence in the world. Creative artists may unconsciously employ magical and mythical images and icons that signify a wider spiritual and cultural context. In this paper, the concept of myths and magic is used as a tool to analyze his stone sculptures.

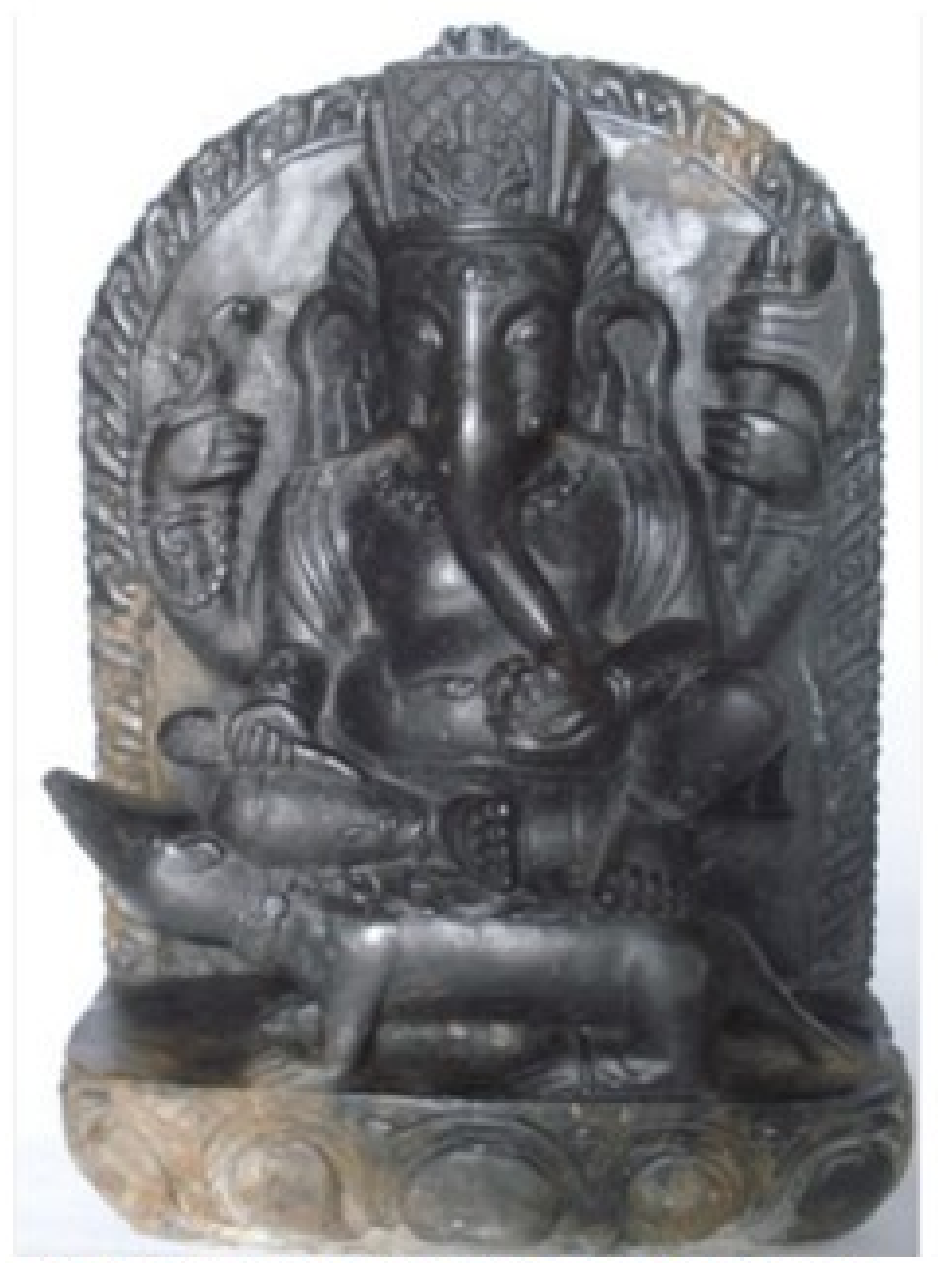

Fig. 1 Chandra Shyam Dangol. Ganesh, 2014

\section{RESULTS AND DISCUSSION}

Dangol's stone sculptures have magical and mystical features that suggest the existence of invisible power in the universe. The artworks inspire the viewers to explore the existence of the self and the world. The artworks imply the union of the self and universe. The symbolic works suggest something else beyond the presented images. In his sculptures, the 
divine figures stand or sit on the lotus flower. This is a magical feature in the sense that the flower is small and soft, and it is almost impossible for the big and heavy figure to stand on it. It is mystical but it has another layer of meaning. Lotus symbolizes purity and enlightenment. This suggests that the divine figures are enlightened. Gaurda (bird) is the vehicle of Lord Vishnu. It is strange that the bird carries the load of Vishnu and flies in the sky. The mouse is the vehicle of Lord Ganesh. Some deities have multiple hands. This is also magical. It signifies that the divine characters can perform multiple tasks at once. This part of the article analyzes the artworks and interprets them in terms of their magical properties and their significance.

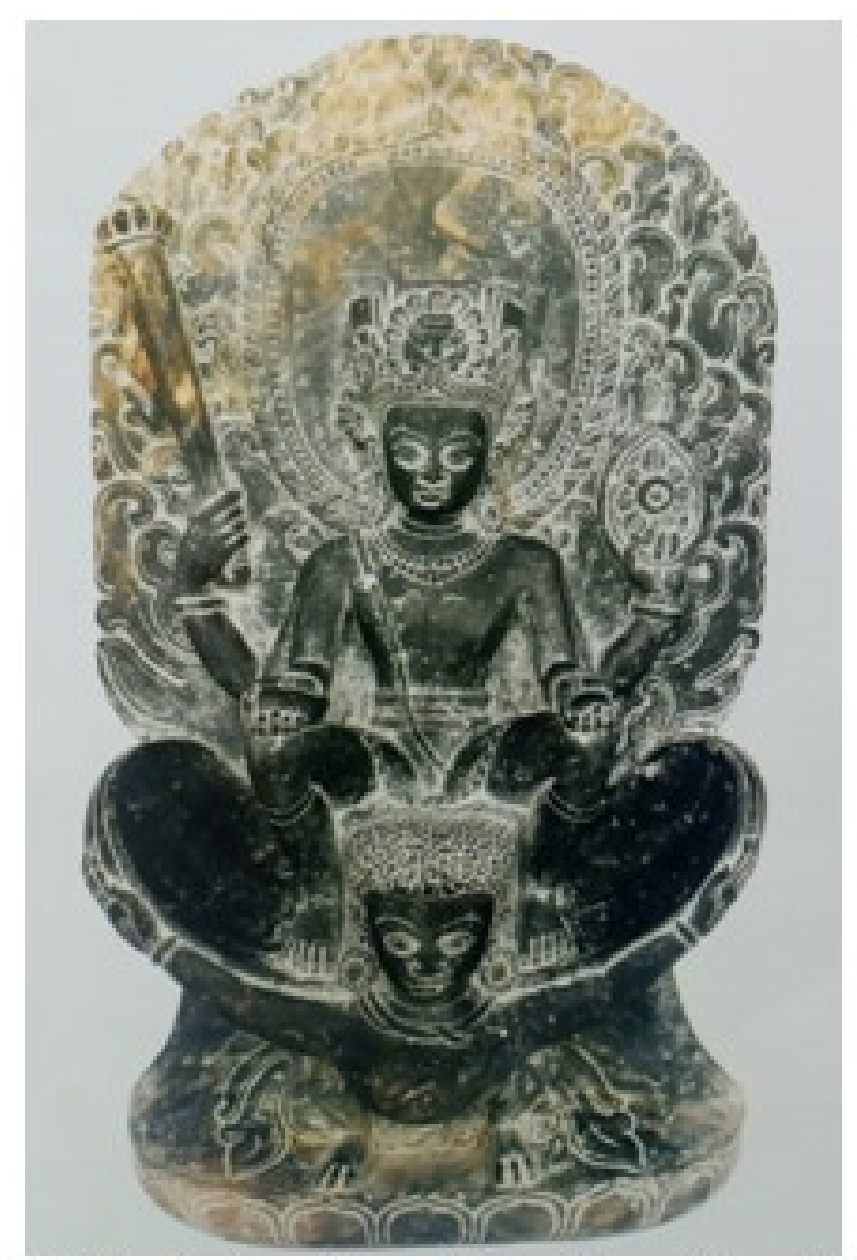

Fig.2 Chandra Shyam Dangol. Garudashan Vishnu, 2016

Dangol's stone sculpture Ganesh (Fig.1) has magical features that signify his supernatural power. The deity with a big belly is on the lotus flower. Lotus is the symbol of enlightenment. The deity on the lotus is believed to have been enlightened. The strange thing is that how the lotus flower can bear the load of the heavy body. He is on the rat, his vehicle. It is unusual that a small rat functions as the vehicle of the god whose body is heavy. It is believed that the rat is the symbol of greed which the divine figure controls. The deity has four hands. It is also a magical aspect since we have never seen a person having four hands. It implies that divinity has supernatural power and can perform multiple tasks at one time. The 
body is the hybrid form of the elephant's head and the human body. This strange combination signifies the existence of both aspects within a person. He has a garland of snake signifying that negative and positive aspects cannot be separated with clarity and distinction. They coexist in the same space. The composition of the symbols in the sculpture signifies the ethical and spiritual values like wisdom, enlightenment and the values of the society. On the surface, the work appears magical but it has underlined logic and convincing significance. (Shakya, 2000).

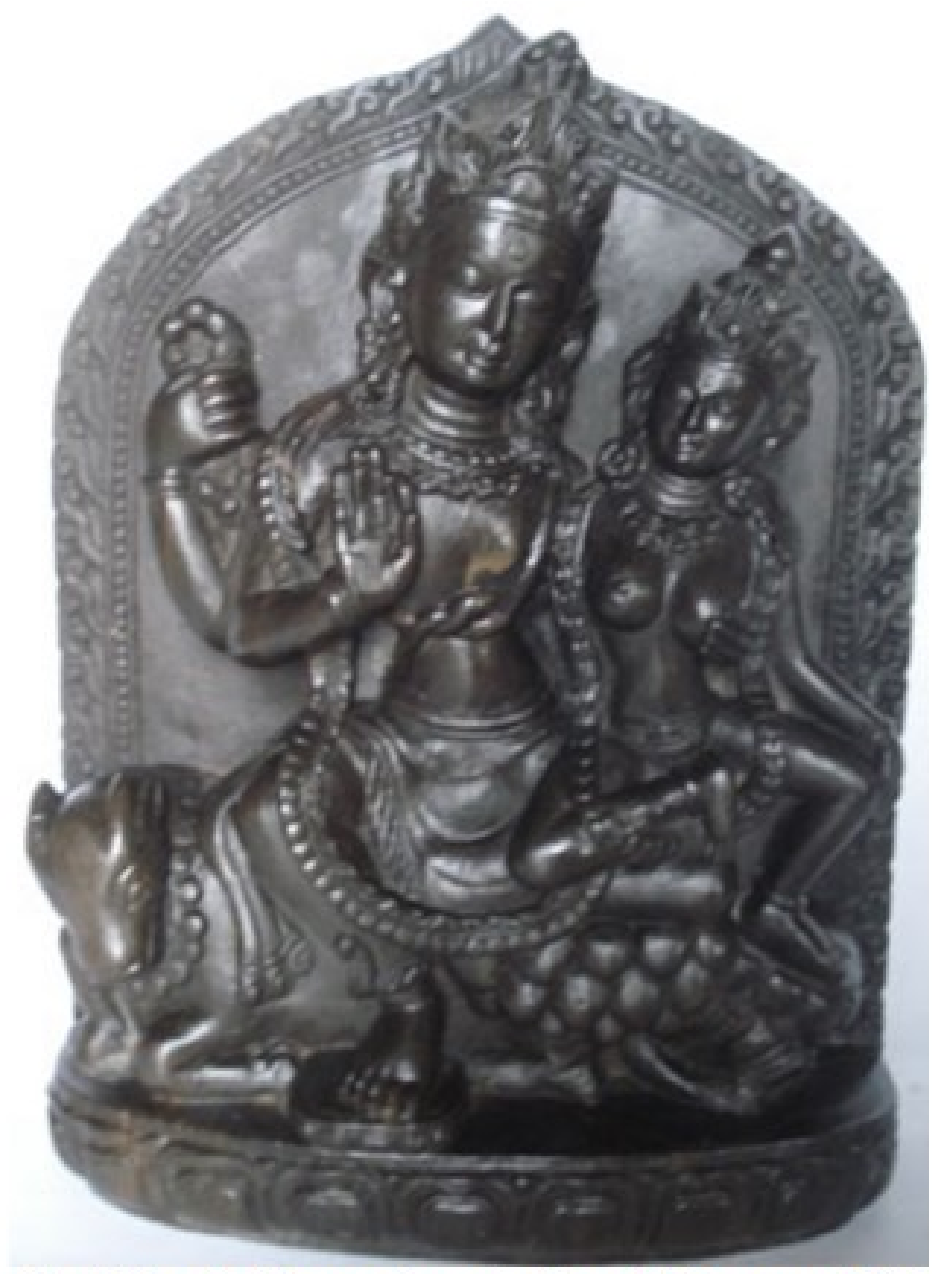

Fig.3 Chandra Shyam Dangol. Uma-Mahesvara, 2018

His Garudashan Vishnu (Fig.2) presents Lord Vishnu on garud (bird). It is magical in the sense that a bird flies in the sky carrying the anthropomorphic deity on its back. In reality, the bird is smaller than the god. Other magical elements are the four hands of the god. The bird has been personified giving anthropomorphic features. The bird has a human face and human hands despite the existence of wings. According to the myths related to Lord Vishnu, garuda is his vehicle. It is believed that Lord Vishnu nourishes all the living beings of the universe (Hamal, 2018). The magical elements suggest his supernatural power.

His sculpture Uma-Mahesvara (Fig.3) presents the union of Uma and Mahesvara. The goddess is sitting on the lap of the god. The figures are also the manifestations of Shiva and 
Shakti or the male and the female principles. The deities are on the bull, the vehicle of Mahesvara. This is the magical element. Mahesvara has four hands suggesting supernatural power (Shah, 2014). A snake is around the body of Shiva as a garland. These are the magical aspects that suggest supernatural power. The union is believed to encompass the entire universe. In the union of Prakriti and Purusa, everything in the universe becomes one (Sharma, 2020,p.167). The duality between the self and the other dissolves.

The individual sadhaka (practitioner) is supposed to realize the state of non-duality through meditation. He is believed to find the entire cosmos within himself. Mainali (2007)states that Shiva is the symbol of absolute bliss (paramananda), he is beyond the beginning and the end, and timeless within time. The sculpture presents the theme of cosmic harmony. The union of Uma and Mahesvara creates cosmic harmony. The union suggests the continuity of life and world (Brown, 1990). The person, who realizes this concept, is supposed to achieve the status of Shiva himself. All the parts of the universe are the integral parts of Uma-Mahesvara. There is no duality between the self and the other, and you and me (Sharma, 2009). All the things are the manifestations of the same entity,Brahman (the cosmic being). Everything is filled with the divine spirit that has created the oneness in them. Khadka (1995, p.31) writes about the unity of the individual self and the universal self:

It is the self that is supreme, self has a double aspect to it: the individual and the universal self, and they can be expressed diversely: the individual self can be regarded as one's smaller self, the universal self as one's larger self, though essentially, there are no smaller or larger selves. They are one self. Recognition of the unity and universality of the self is one of the major metaphysical ends of Hinduism. There is no duality of subject/object.

Khadka(1995) further says that an individual soul identifies with the supreme soul or Brahman. When the individual self or yogi assimilates and identifies oneself with the Brahman or cosmic being, he experiences "one life, one world, one existence" (Vivekananda, 1915,p.295). Then the individual self visualizes himself in every image of the world. He finds Brahman within himself, and himself within Brahman. A person becomes all-embracing consciousness which is at once Being and Bliss (Khadka,1995, p.55). Dangol'sUma-Mahesvar is the symbol of the union of the Purusa and Prakriti or the self and the other (Rae, 1994). His stone sculptures present spiritual concepts and ideas in a magical and mystical manner. 


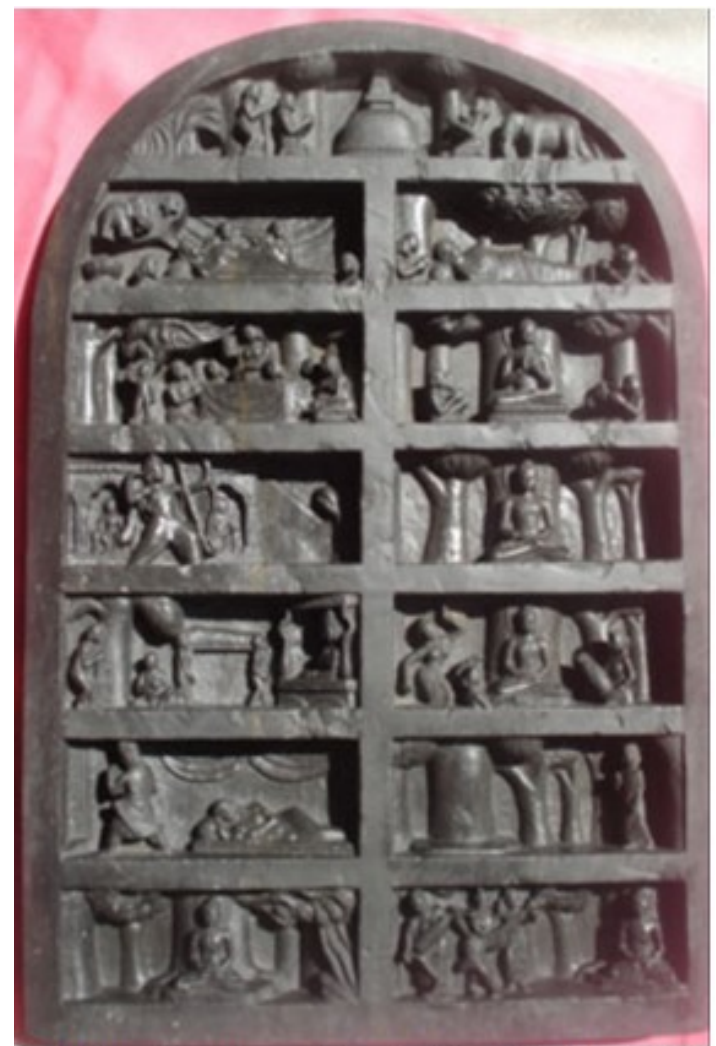

Fig.4 Chandra Shyam Dangol. Life of Buddha, 2006

Dangol's stone sculpture Life of Buddha (Fig.4) narrates the magical events in Buddha's life. The work includes scenes like the birth of Buddha, meditation under the bodhi tree, Mara's temptation and attack, visiting mother after his enlightenment, taming mad elephant and mahaparinirvana (the last departure). In the scene of Buddha's birth, Buddha comes out from Maya Devi's hip, walks his first seven steps and stands on the pyramid of lotuses (Hirakawa, 1990). The young child performs a miraculous activity. This suggests his supernatural power and enlightenment (Chitrakar, 2018). The figure of the young Buddha looks tall. His seven steps after the birth and his standing on the pile of lotuses are signs of his mystical journey from this world to the stage of enlightenment (Conze,1973). After his enlightenment, he goes to heaven and visits his mother. He also tames mad elephant with his spiritual power. These events are magical and mystical suggesting supernatural aspects of the Buddha.

\section{CONCLUSION}

Dangol's stone sculptures are magical and mystical. The use of lotus flower as a seat for divine figures, multiple hands of deities, rat and bird as their vehicles, and supernatural activities of the mythical characters are the magical aspects in his stone sculptures. They symbolize spiritual ideas related to the harmonious coexistence of the individual in the world along with other living beings. The characters and images in the sculptures suggest beyond concrete visuals. Lotus symbolizes purity and enlightenment. Figures of Uma-Mahesvara suggest the unity and oneness of all the things in the universe. The sculpture is the symbol of the union of the self and the absolute spirit. The figures of Ganesh and Vishnu also appear magical due to their multiple hands and their vehicles. The artworks suggest the omniscient 
and omnipotent characters of divinity. On the surface, the works appear magical but close analysis reveals the underlined logic in the myths. The focus is on discerning the self and the universe around for harmonious existence in the world. By scrutinizing the works, the curious viewers are likely to move toward the exploration of the myths and spiritual dimensions.

\section{REFERENCES}

Bajracharya, N. M. (2018). Inheritance - Chandra Shyam Dangol's solo sculpture exhibition. In Exhibition catalogue, Khokan Stone Carving, 12-13.

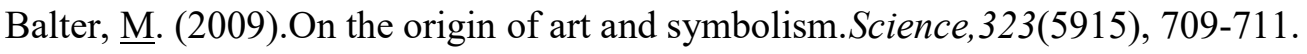

Brown, M. (1990). The triumph of the goddess. State University of New York Press.

Campbell, J. (1971). The portable Jung.Viking.

Chitrakar, M. (2018). Chandra Shyam Dangol's inheritance: Tradition revisited. In Exhibition catalogue, Khokan Stone Carving, 3-5.

Conze, E. (1973). The short Prajnapramita texts.Luzac\& Co.

Dixit, G. (2011, March). Man of stone: Chandra Shyam Dangol. ECS Nepal: The Nepali way, p.96

Frye, N. (1992). Anatomy of criticism. In H. Adams(Ed.), Critical theory since Plato (pp. 1046-1072). Harcourt Brace Jovanovich College.

Gorkhapatra Daily. (2018, June 20). PradarsanimaDangolkamurtikala.

Gurung, P. (2019, August). The return of Manjushree.ECS Nepal: The Nepali way, 28-31

Hamal, C. (2018, August 4). Dhungemurtikokalatmakaayam.Nagarik.p. ka

Hirakawa, A. (1990). A history of Indian Buddhism from Sakyamuni to early Mahayana.University of Hawaii Press.

Jung, C.G. (1992). On the relation of analytical psychology to poetry. In H. Adams(Ed.), Critical theory since Plato (pp. 784-791). Harcourt Brace Jovanovich College.

Kantipur National Daily. (2018, June 21). DhungamaLichchhabikaal.

Khadka, G. (1995).Whitman's system of dynamic meditation: A tantric guide to his work. [Unpublished $\mathrm{PhD}$ dissertation].Tribhuvan University. Kathmandu, Nepal.

Khokana Stone Carving. Chandra Shyam Dangol. 2021. https://www.stonecarvingnepal.com/about/team-single/?id=1782

Langer, S. K. (1979). Philosophy in a new key: A study in the symbolism of reason, rite, and art. Harvard UP.

Mainali, L. (2007). Saswat. In Exhibition Catalogue, The Art Shop.

Nagarik Daily. (2018, June 20). Chandraka dhunge murtima Lichchhabikalin jhajhalko.

Paudyal, A. (2018, June 23). Kalakarko Manama murti bannu parchha. Annapurna post.

Rae, E. (1994). Women, the Earth, the divine.Orbis Books.

Rampley, M. (1997). From symbol to allegory: Aby Warburg's theory of art. The Art Bulletin, 79 (1), 41-55.

Shah, U. (2014, May 11). Mission murtikala.Nepal: National weekly, 14 (39), 10.

Shakya, M. B. (2000). Sacred art of Nepal.Handicraft Association of Nepal.

Sharma, Y. P. (2009). Contemporary Nepali paintings: Hybridity and negotiations. [Unpublished $\mathrm{PhD}$ dissertation]. Tribhuvan University.Kathmandu, Nepal. https://elibrary.tucl.edu.np/handle/123456789/5965 
Sharma, Y. P. (2021). Archetypes in Batsa GopalVaidya's paintings. SIRJANĀ-A Journal on Arts and Art Education, 7(1), 66-73. https://doi.org/10.3126/sirjana.v7i1.39353

Sharma, Y. P. Tracing the traditional contents and forms in contemporary Nepali paintings.Molung Educational Frontier, $10 \quad$ (1), 2020, 169-180. https://doi.org/10.3126/mef.v10i1.34040

Shrestha, S. (2018, June 17). A permanent home for a megalithic Manjushree.Republica, p. i Sourya National Daily. (2018, June 21). ChandrashyamkaLichchhabikaalinprastarmurti.

Thapa, A. (2016, July 22). Resurrecting Manjushree.M\&S VMAG, 18-20. http://mnsvmag.com/news/2016-07-22/resurrecting-manjushree$\underline{20160818162638 . h t m l}$

Tourism Mail. (2018, July 1). Sculptor Chandra Shyam Dangol conducts exhibition of latest sculptures.https://www.tourismmail.com/sculptor-chandra-shyam-dangol-conductsexhibition-of-latest-sculptures

Vivekananda, S. (1915).The complete works of Swami Vivekananda.Advaita Ashram.

Ward, W. E. (1952). The lotus symbol: Its meaning in Buddhist art and philosophy. The Journal of Aesthetics and Art Criticism, 11(2), 135-146. 